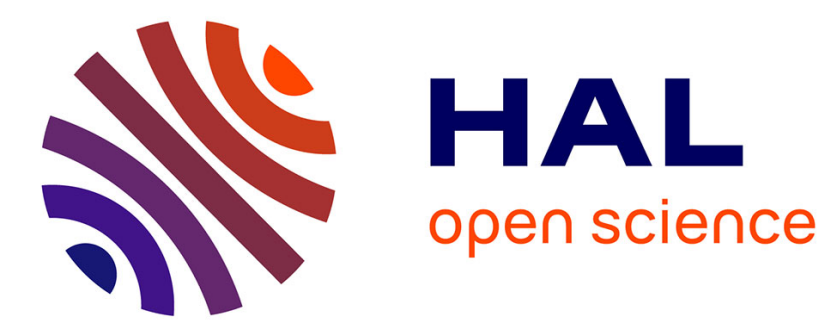

\title{
Crossing a two-way street: comparison of young and old pedestrians
}

Aurélie Domnes, Viola Cavallo, Jean Baptiste Dubuisson, Isabelle Tournier, Fabrice Vienne

\section{> To cite this version:}

Aurélie Domnes, Viola Cavallo, Jean Baptiste Dubuisson, Isabelle Tournier, Fabrice Vienne. Crossing a two-way street: comparison of young and old pedestrians. Journal of Safety Research, 2014, 50, pp 27-34. hal-00984641

\section{HAL Id: hal-00984641 \\ https://hal.science/hal-00984641}

Submitted on 28 Apr 2014

HAL is a multi-disciplinary open access archive for the deposit and dissemination of scientific research documents, whether they are published or not. The documents may come from teaching and research institutions in France or abroad, or from public or private research centers.
L'archive ouverte pluridisciplinaire HAL, est destinée au dépôt et à la diffusion de documents scientifiques de niveau recherche, publiés ou non, émanant des établissements d'enseignement et de recherche français ou étrangers, des laboratoires publics ou privés. 
Journal of Safety Research, vol 50, septembre 2014, pp 27-37

Auteurs : A.Domnes, V.Cavallo, JB. Dubuisson, I.Tournier, F.Vienne

Crossing a two-way street: comparison of young and old pedestrians

\begin{abstract}
Introduction: Choosing a safe gap in which to cross a two-way street is a complex task and only few experiments have investigated age-specific difficulties. Method: A total of 18 young (age $19^{-} 35$ ), 28 younger ${ }^{-}$old (age $62^{-} 71$ ) and 38 older $^{-}$old (age $72-85$ years) adults participated in a simulated street-crossing experiment in which vehicle approach speed and available time gaps were varied. The safe and controlled simulated environment allowed participants to perform a real walk across an experimental two-way street. The differences between the results for the two lanes are of particular interest to the study of visual exploration and crossing behaviors. Results: The results showed that old participants crossed more slowly, adopted smaller safety margins, and made more decisions that led to collisions than did young participants. These difficulties were found particularly when vehicles approached in the far lane, or rapidly. Whereas young participants considered the time gaps available in both lanes to decide whether to cross the street, old participants made their decisions mainly on the basis of the gap available in the near lane while neglecting the far lane. Conclusions: The present results point to attentional deficits as well as physical limitations in older pedestrians and have implications in terms of road design and pedestrians training.
\end{abstract}

Keywords: Street-crossing; Aging; Virtual environment 


\section{Introduction}

Deciding when it is safe to cross a street in relation to available traffic gaps is a complex everyday task involving several functional abilities known to decline with aging (Knoblauch, Pietrucha, \& Nitzburg, 1996; Salthouse, Atkinson, \& Berish, 2003; Snowden \& Kavanagh, 2006). Age-related declines in perceptual, cognitive, and physical abilities have been shown to result in non-optimal street-crossing decisions and behaviors (Dommes \& Cavallo, 2011; Dommes, Cavallo, \& Oxley, 2013; Dunbar, Holland, \& Maylor, 2004) and may contribute to the high rate of fatal or serious-injury crashes found for old pedestrians (ONISR, 2011).

Since the 90's, an increasing number of studies have been examining the characteristics of pedestrians (such as age) and/or the traffic environment (such as the number of lanes and the speed of approaching cars) likely to raise the risk of a pedestrian being involved in an accident when crossing the street. The pioneer observational study by Oxley et al. (1997) showed that the higher number of unsafe street crossing decisions among pedestrians over 65 years of age occurred mostly in complex traffic situations such as two-way undivided streets, whereas their street-crossing safety improved significantly in less complex situations such as one-way streets. As shown in a French accident study, old pedestrians are more likely to be hit during the second half of the crossing, i.e., on the far side of the road (Fontaine \& Gourlet, 1997). Dunbar $(2005,2012)$ analyzed road-accident data from Great Britain but obtained different findings by observing an especially high risk of accidents among the oldest pedestrians on the near side of the street.

Although age-specific difficulties handling traffic approaching from several directions are worth investigation in view of making older pedestrian street-crossing safer, only a few papers have studied them experimentally. This is the aim of the present study. To our knowledge, some rare observational studies (Oxley et al., 1997; Zhuang \& Wu, 2011, 2012) and accident analyses (Fontaine \& Gourlet, 1997; Dunbar, 2012) have been dedicated to old 
pedestrians in two-way road traffic situations but faced up to difficulties when attempting to specifically examining the role of precise traffic- or pedestrians-related characteristics because they were conducted in real-life situations where these factors could not be experimentally manipulated.

Although laboratory studies are unlikely to give a perfect assessment of the frequency of unsafe choices in the real world (Holland \& Hill, 2010), they are helpful in controlling factors such as traffic. To our knowledge, there are only two experimental studies about two-way street crossings, but they used judgment tasks where participants indicated their choices by pressing a response button (Dommes et al., 2013) or taking one step forward (Holland \& Hill, 2010). In these studies, the pedestrians did not carry out a crossing task, so the actual behaviors in each of the two lanes of the street (such as walking speed, acceleration, and safety margin) could not be studied. However, the Holland and Hill (2010) study revealed an interesting finding which we propose to further examine here using a task that allows for an actual two-way crossing: looking at the far lane immediately before stepping out was associated with safer road-crossing choices, and this behavior was executed the least often by old pedestrians. The authors assumed, in accordance with Oxley et al. (1997) and Fontaine and Gourlet (1997), that old adults have trouble taking into account the far side of the road before beginning to cross and are thus more often involved in far-lane collisions than younger pedestrians are. But because the participants were not actually walking, the old pedestrians could not compensate for the selection of incorrect gaps by walking faster. Moreover, participants were watching videos of real approaching cars, so characteristics of the traffic environment like speed could not be studied, even though these characteristics are known to be an important risk factor in aging pedestrians.

Most experimental studies on old pedestrians concern one-way crossings (Lobjois \& Cavallo, 2007, 2009; Lobjois, Benguigui, \& Cavallo, 2013; Oxley, Ihsen, Fildes, Charlton, \& 
Day, 2005). As in observational studies, old adults are found to adopt shorter safety margins, especially when the speed of the approaching vehicles is high, with more unsafe decisions at higher speeds than lower speeds in simulated one-way traffic environments. Most likely because of diminished perceptual and cognitive abilities (Dommes \& Cavallo, 2011), old people appear to use simplifying heuristics based primarily on the distance of the approaching car instead of on the time gap, which young pedestrians appear to use (Lobjois \& Cavallo, 2007, 2009; Oxley et al., 2005). Because an approaching vehicle is farther away at a high speed than at a low one for a given available time gap, older people more often decide that it is safe to cross, walk more slowly, and choose to cross in shorter safety margins when the speed of the approaching vehicle is high. The use of distance-based heuristics is related to an overestimation of the available time and thus to very dangerous crossing behaviors. The misperception of time-to-arrival in older adults has even been shown to be a predictor of unsafe crossings in one-way traffic situations (Dommes \& Cavallo, 2011).

The aim of the present study was to gain a better understanding of the risk factors that heighten the probability that old pedestrians will be involved in a collision when crossing a two-way street. The present study experimentally investigates the effects of age, time gap availability in each lane, and speed of approaching cars, in a safe and controlled simulated environment where participants walk on an experimental two-way road. Differences in the results for the two lanes are of particular interest to the study of looking and crossing behaviors. Because of age-related perceptual, cognitive, and motor limitations, and in line with Oxley et al. (1997) as well as Fontaine and Gourlet (1997), old pedestrians are expected to experience more difficulty than young pedestrians in selecting safe gaps in the far lane of traffic and in compensating for risky decisions by increasing their walking pace during crossing. According to earlier works (Lobjois \& Cavallo, 2007, 2009; Oxley et al., 2005), a 
higher number of unsafe crossings as speed increases should also be observed in old pedestrians.

\section{Method}

\subsection{Participants}

A total of 84 participants took part in the experiment: 18 young adults ranging in age between 19 and 35 years $(M=29.17, S D=4.73), 28$ younger-old adults ranging between 62 and 71 years $(\mathrm{M}=68.11, \mathrm{SD}=2.41)$, and 38 older-old adults ranging between 72 and 85 years $(M=75.68, S D=3.31)$. The younger-old and older-old groups were respectively below and above the median age (72 years old) and the mean age (72.5) of all old participants. The young group was comprised of 8 women and 10 men, the younger-old, of 22 women and 6 men, and the older-old, of 28 women and 10 men.

All participants had normal or corrected-to-normal binocular visual acuity (at least 6/10, Ergovision, Essilor $\left.{ }^{\circledR}\right)$. Walking speeds were also measured ${ }^{1}$. Older-old participants $(\mathrm{M}=1.21$ $\mathrm{m} / \mathrm{s}, \mathrm{SD}=0.15)$ and younger-old participants $(\mathrm{M}=1.23 \mathrm{~m} / \mathrm{s}, \mathrm{SD}=0.14)$ walked more slowly than young participants $(\mathrm{M}=1.57 \mathrm{~m} / \mathrm{s}, \mathrm{SD}=0.09)$; these walking speeds are in accordance with several field studies (see e.g., Knoblauch et al., 1996). Participants in the older groups specifically took the MMSE test (Folstein et al., 1975) to ensure the absence of pathological aging symptoms. All were in good health (screened by self-report), were living at home, and went out regularly without help. The study was approved by the institutional ethics committee.

\footnotetext{
${ }^{1}$ Walking speed over a distance equivalent to the width of the simulated street (5.70 meters materialized on the ground by two markers) was measured in the simulator room (but with no virtually approaching cars) on six trials at a normal to fast walking pace.
} 


\subsection{Experimental setup}

The street-crossing simulation device included a portion of a real experimental street (5.7 $\mathrm{m}$ wide, indicated by continuous grey markings on the floor, used also to demarcate the edge of the flat virtual sidewalks), an image-generation system, a rear-screen projection system, a 3D sound-rendition system, and a movement recording system. The visual scenes were projected on ten screens ( $2.55 \mathrm{~m}$ high and $1.88 \mathrm{~m}$ wide) forming a corridor in which the pedestrian could walk up to 7 meters (see Figure 1). The setup provided the pedestrian with a horizontal visual field between $180^{\circ}$ (at the starting point of the crossing) and $300^{\circ}$ (in the middle of the street and at the sidewalk on the other side), and a vertical visual field of $40^{\circ}$. The pedestrian's initial position was such that s/he could watch the traffic coming from both directions by turning her/his head to the left or right (see Figure 1). S/he was standing at the edge of a sidewalk, facing the experimental street, and had to walk to the other side of the street when s/he thought it was safe to do so. The images (60 frames per second) were

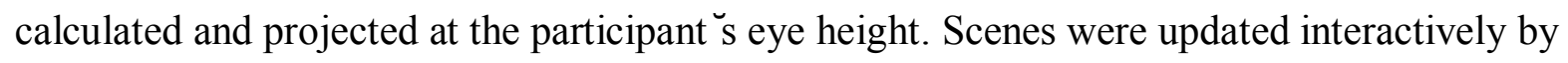

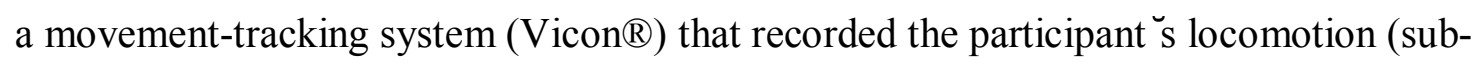
millimeter accuracy) and head motion.

\section{[FIGURE 1]}

The visual scenes represented a two-way street 5.70 meters wide sidewalk-to-sidewalk. Traffic consisted of groups of motorcycles and cars (between 5 and 10 vehicles). The direction of the traffic followed the French traffic rules: on the near-side lane, the flow of vehicles was approaching from the left of the pedestrian standing on the sidewalk. Vehicles in the far lane were approaching from the right. 


\subsection{Procedure and experimental task}

Participants were tested individually on the street-crossing simulator. For each trial, they had to judge whether the available gaps in the approaching traffic where suitable for crossing the street. They were instructed to choose traffic gaps in which they could cross the entire two-way street without running and/or stopping in the middle of the street. If they thought it was safe to do so, they were instructed to cross. Otherwise they waited for the next trial. The

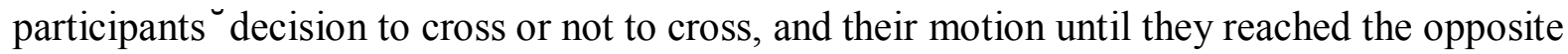
sidewalk were recorded.

The experimenter began the session by describing the basic principles of the street-crossing simulator. Then the participant performed a maximum of 18 practice trials. The practice trials were stopped when the participant was comfortable and fully understood the task. The participant then performed the experimental street-crossing task composed of 2 blocks of 18 trials.

Vehicle speed (40 or $60 \mathrm{~km} / \mathrm{h}$ ) and time gap between two target cars in each of the two traffic flows (from 1 to $5 \mathrm{~s}$, in 1 -s increments) were varied. Table 1 describes the manipulated time gaps between the two target cars. These gaps were always synchronized and thus simultaneously available in both lanes. The time gaps always appeared $6 \mathrm{~s}$ after the onset of the trial, providing a view of the traffic scenes for $6 \mathrm{~s}$ before participants could cross (see Figure 1). All other vehicles in the traffic groups were separated by about $1.5 \mathrm{~s}$ so that participants could not cross between them. The 17 time-gap combinations (see Table 1) and the 2 speeds of approaching cars resulted in a total of 34 trials. They were presented in random order in 2 blocks, with a break between the blocks. one time gap combination $(3 \mathrm{~s}$ in each lane) was repeated to make the link between the two blocks, making a total of 36 trials. The street-crossing task took about 30 minutes to complete.

[TABLE 1] 


\subsection{Data analysis}

Six measures were considered. The first was accepted crossings, and the other five were derived from the movement-tracking system and measured head movements and distance travelled.

- Accepted crossings: trials were scored as to whether the participant did or did not accept the available gaps for crossing the street.

- Number of looks: the number of looks in the direction of each lane were counted before the participant began to cross.

- Looking time: the time spent looking at traffic approaching in each lane of the two-way street was measured before the participant crossed the street.

- Collisions: a crossing was scored as a collision when the participant was virtually hit by the approaching car: s/he was in front of the approaching car (within the width of the front end of the car) when it passed the crossing line. This variable was calculated for the near and the far lanes of the two-way street and was expressed as percentage of the total number of crossings accepted by the participant.

- Crossing time: crossing time was calculated for each crossing performed (without leading to a collision) and each lane of the two-way street. Crossing time for the first lane was equal to the time between when the participant started to walk and when s/he had finished crossing that lane (i.e., in the middle of the street); crossing time for the far lane was equal to the time between when the participant was in the middle of the street and when s/he arrived the opposite sidewalk.

- Safety margin: safety margin was calculated for each crossing and each lane of the street. Safety margin was measured as the time between when the participant had gone past the path of the approaching car (width of the front end of the approaching car) and when the front end 
of the car reached the crossing line. In other words, safety margin was the time left before a collision.

Accepted crossings were analyzed through logistic regressions. The other five behavioral indicators were entered into a multivariate analysis of variance (MANOVA). MANOVA is a more appropriate analysis than independent ANOVAs for cases where there is a moderately high correlation between the dependent variables (Tabachnick \& Fidell, 1989). The significance level was set at .05. Wilks ` multivariate statistic $\notin$ was used. Wilks `lambda ranges from 0 to 1 ; the lower it is the more the given effect contributes to the model. The partial eta-squared statistic $\left(:_{p}^{2}\right)$ was used as an index of the relative effect size. Effects found to be significant in the MANOVA were tested against each of the dependent measures using univariate analyses. Fisher LSD post-hoc tests were performed to determine the source of the significant effects.

\section{Results}

\subsection{Crossing decisions}

The participants responses are plotted in Figure 2 as a function of age group and the time gap available in each lane.

\section{[FIGURE 2]}

Based on the raw data, this figure shows different decision-making behavior for young and old participants. Contrary to old participants, young participants considered the available time gaps in both lanes in deciding whether or not to cross the two-way street: when the time gap available in the near lane was long (5s) but short in the far lane (2s), most of the young participants refused to cross (on average 14\% acceptance). In contrast, both groups of old participants decided to cross much more often (on average $72 \%$ acceptance). Both old groups systematically increased the percentage of accepted crossings based on the time gap available in the near lane(Figure 2), while neglecting the one available in the far lane. Their crossing 
criteria therefore seem to be different, with whole-road choices by young pedestrians and biased near-lane choices by old pedestrians.

To look further into this hypothesis, logistic regressions were computed on each age group's gap acceptance as a function of the time gap available in each lane. Data relative to younger-old and older-old participants were combined into one.

The model was significant in the young group of participants, $\$(2)=244.95, p<.001$, $R^{2}=.42$. Both the time gap available in the near lane (Wald statistic $=80.301, \mathrm{p}<.001$ ) and the time gap available in the far lane (Wald statistic $=101.81, \mathrm{p}<.001)$ were significant predictors of the choices made by young participants. Indeed, the near-lane time gap (odds ratio=2.35) and the far-lane time gap (odds ratio=2.67) were equally powerful in predicting the young participants' decision to cross the two-way street.

The model was also significant in the old group of participants, $\$(2)=1075.62, p<.001$, $R^{2}=.49$. Here again, time gap available in the near lane (Wald statistic $\left.=582.98, \mathrm{p}<.001\right)$ and the time gap available in the far lane (Wald statistic $=44.79, \mathrm{p}<.001$ ) were both significant predictors of the choices made by the old participants. But the near-lane time gap played a much more important role (odds ratio $=4.23$ ) than the far-lane time gap (odds ratio=1.39) in predicting the old participants' decision to cross the two-way street.

\subsection{Crossing behaviors}

The 3 (age groups: young, younger-old, and older-old participants) x 2 (lanes: near and far lanes) x 2 (speeds: 40 and $60 \mathrm{~km} / \mathrm{h}$ ) MANOVA revealed a multivariate main effect of age group, $\notin=.29, F(10,154)=13.31, p<.0001,: 2=.46$. Univariate analyses indicated that four dependent measures contributed to the multivariate main effect, i.e., looking time $\mathrm{F}(2,81)=32.5, \mathrm{p}<.001, \quad:_{\mathrm{p}}^{2}=.45 ;$ collisions $\mathrm{F}(2,81)=10.69, \mathrm{p}<.001, \quad{ }^{2} \mathrm{p}=.21$; crossing time $\left.\mathrm{F}(2,81)=8.71, \mathrm{p}<.001, \quad{ }_{\mathrm{e}}^{2}=.18\right) ;$ and safety margin $\mathrm{F}(2,81)=2.78, \mathrm{p}=.067, \quad{ }_{\mathrm{p}}^{2}=.06$. Post-hoc analyses indicated greater difficulty in both groups of old participants. Although before 
crossing, both groups of old participants looked significantly longer at the traffic than young participants did (see Figure 3), they made significantly more decisions that led to collisions with an approaching car (see Table 2). Crossings were slower and less safe than among young participants (see Tables 3 and 4). Whereas older-old participants had more collisions than younger-old participants, there were no significant differences between the two groups of old participants in looking time, crossing time or safety margin.

\section{[FIGURE 3]}

\section{[TABLES 2, 3 and 4]}

The results showed a multivariate main effect of lane, $\notin=.14, F(5,77)=96.39, p<.0001$, $:_{\mathrm{p}}^{2}=$.86. All five behavioral measures contributed to the multivariate effect, i.e., number of looks $\mathrm{F}(1,81)=8.35, \mathrm{p}<.01, \quad:^{2}=.10$; looking time $\mathrm{F}(1,81)=50.26, \mathrm{p}<.0001, .2 . \mathrm{p}=.38$; collisions $\mathrm{F}(1,81)=25.96, \mathrm{p}<.001, \quad:_{\mathrm{p}}^{2}=.24$; crossing time $\mathrm{F}(1,81)=257.42, \mathrm{p}<.001, \quad:_{\mathrm{p}}^{2}=.76$; and safety margin $\mathrm{F}(1,81)=93.85, \mathrm{p}<.001, \stackrel{2}{2}=.54$. Overall, univariate analyses showed greater difficulty in the far lane of the two-way street. Whereas participants made more head movements in the direction of the far lane, they looked longer at the near lane (see Figure 3). Participants had more collisions mostly in the far lane than in the near lane (see Table 2). Participants seemed to have tried to avoid imminent danger in the far lane because crossings were faster and less safe in the far lane than in the near lane (see Tables 3 and 4).

The multivariate main effect of speed was also significant, $\notin=.35, F(5,77)=28.55, p<.0001$, $:_{\mathrm{p}}^{2}=.65$. Three dependent measures contributed to this effect, i.e., looking time $\mathrm{F}(1,81)=33.92, \mathrm{p}<.001,::_{\mathrm{p}}^{2}=.30$; collisions $\mathrm{F}(1,81)=8.02, \mathrm{p}<.01, \stackrel{2}{:}=.09$; and safety margin $\mathrm{F}(1,81)=119.13, \mathrm{p}<.001, \quad:_{\mathrm{p}}^{2}=.60$. The effect of speed on crossing time was marginal $(\mathrm{F}(1,81)=3.15, \mathrm{p}=.08)$. All of these univariate analyses concur in revealing difficulty handling the high speed of approaching cars during street crossing. Although participants looked slightly longer at the traffic when cars were approaching at the high speed $(M=2.45 \mathrm{~s}$, 
$\mathrm{SD}=1.05)$ than at the low speed $(\mathrm{M}=2.32 \mathrm{~s}, \mathrm{SD}=0.90)$, they experienced more collisions at 60 $\mathrm{km} / \mathrm{h}$ than at $40 \mathrm{~km} / \mathrm{h}$ (see Table 2). Participants did not seem to be aware of the fast arrival of the approaching car, because crossing times were longer and safety margins shorter at 60 $\mathrm{km} / \mathrm{h}$ than at $40 \mathrm{~km} / \mathrm{h}$ (see Tables 3 and 4 ).

The multivariate interaction between age group and lane was significant, $\notin=.29$, $F(10,154)=13.24, p<.0001, \quad{ }_{\cdot}^{2}=.46$. All five dependent measures contributed to this interaction, i.e., number of looks $\mathrm{F}(2,81)=60.50, \mathrm{p}<.0001, \quad .2=.60$; looking time $\mathrm{F}(2,81)=33.52, \mathrm{p}<.0001, \stackrel{2}{.} \mathrm{p}=.45$; collisions $\mathrm{F}(2,81)=3.22, \mathrm{p}<.05, \stackrel{2}{.} \mathrm{p}=.07$; crossing time $\mathrm{F}(2,81)=7.5, \mathrm{p}<.01, \stackrel{2}{:}=.16$; and safety margin $\mathrm{F}(2,81)=4.24, \mathrm{p}<.05, \stackrel{2}{:}=.09$. Post-hoc tests revealed greater difficulty in both groups of old participants in considering the far lane of the two-way street. Whereas young participants looked significantly more often and longer at the far lane than the near lane before deciding to cross, old participants looked more often and longer at the near lane (see Figure 3). Both old groups obtained many more collisions on the far lane than on the near lane, whereas the percentage of collisions did not vary significantly by lane among the young group of participants. Indeed, significant age-related differences were observed only in the far lane, where both groups of old participants had more collisions than did young participants, and the older-old had significantly more collisions than the younger-old. Post-hoc tests indicated significant lane differences between the three groups of participants, for both crossing time and safety margin. Interestingly, post-hoc test results indicated that young participants crossed the far lane significantly faster than did younger-old and older-participants, whereas no age-related differences were found in the near lane. By walking faster, maybe young participants tried to avoid potential collisions in the far lane, whereas older ones could not avoid them because of their limited ability to increase their gait. In fact, the age-related differences in safety margin were significant only in the near lane, where both groups of old participants adopted smaller safety margins than young participants 
did. In the far lane, the young participants had safety margins that were as small as the younger-old and older-old margins ( $\mathrm{p}=.54$ and $\mathrm{p}=.95)$, but they avoided many more collisions than the older ones did.

The multivariate interaction between age group and speed was also significant, $\notin=.77$, $F(10,154)=2.18, p<.05, \quad{ }_{\mathrm{p}}^{2}=.12$. Univariate analyses yielded a significant interaction only on two of the five measures, i.e., collisions $F(2,81)=3.21, p<.05, \quad{ }^{2} \mathrm{p}=.07$; and crossing time $\mathrm{F}(2,81)=7.12, \mathrm{p}<.01,::_{\mathrm{p}}^{2}=.15$. Whereas speed differences were not significant in the young group or the younger-old group, older-old participants had more collisions at $60 \mathrm{~km} / \mathrm{h}$ than at $40 \mathrm{~km} / \mathrm{h}$. Age-related differences were significant at $60 \mathrm{~km} / \mathrm{h}$ only. Regarding crossing time, post-hoc tests yielded no significant speed differences in the young group, whereas both groups of old participants crossed more slowly at $60 \mathrm{~km} / \mathrm{h}$ than at $40 \mathrm{~km}$.

The multivariate interaction between lane and speed was significant, $\notin=.79, F(5,77)=3.97$, $p<.01, \quad{ }_{\mathrm{p}}^{2}=.21$, as was the multivariate interaction between age group, lane and speed $\notin=.79$, $F(10,154)=1.94, p<.05, \stackrel{2}{.} \mathrm{p}=.04$. Regarding the latter interaction, univariate analyses yielded a significant interaction only on one of the five measures, i.e., safety margin $F(2,81)=4.87$, $\mathrm{p}<.05, \quad{ }^{2} \mathrm{p}=.11$. Whereas no significant group differences appeared in the far lane, age-related differences were observed in the near lane only at $60 \mathrm{~km} / \mathrm{h}$, where older-old participants adopted smaller safety margins than younger-old and young participants did. In contrast, group differences were not significant at $40 \mathrm{~km} / \mathrm{h}$ in the near lane.

\section{Discussion}

The present study was aimed at investigating the effects of age, available time gap in each lane, and speed of approaching cars on the way a pedestrian chooses a gap during which to cross on a two-way street. The differences between the results for the two lanes are of particular interest to the study of visual exploration and crossings behavior. 
In line with previous research using estimation tasks (Dommes et al., 2013; Holland \& Hill, 2010) or with accident and observational data collected in real-world environments (Fontaine \& Gourlet, 1997; Oxley et al., 1997), the situation of two-way street crossing proved to be a particularly difficult task for old adults. Older-old pedestrians ages 72 to 85 were found to make street-crossing decisions that led to collisions with approaching cars more often than younger-old (ages $62^{-} 71$ ) and young (ages 19-35) participants. This age effect is also in line with the French crash statistics (ONISR, 2011) indicating that people over 75 make up the most vulnerable pedestrian group, accounting for more than $37 \%$ of fatalities although representing less than $9 \%$ of the population. Younger-old and older-old participant groups were also found to cross more slowly and to use smaller safety margins than young participants. This result corroborates those previously obtained in experimental one-way traffic studies using similar behavioral indicators to assess street crossing (Dommes \& Cavallo, 2011; Lobjois \& Cavallo, 2007, 2009).

Also in line with real-world observations and accident studies (Fontaine \& Gourlet, 1997; Oxley et al., 1997) or with analyses conducted on real traffic scenes (Holland \& Hill, 2010), the results of the present experimental study showed that the old groups' difficulties occurred mostly in the far lane of the two-way street. Biased decision-making favoring the nearer lane was observed: both groups of old participants looked more often and longer at the near lane than at the far lane, and regression analyses showed that they based their crossing decisions much more often on the gap available in the near lane, while neglecting the gap available in the far lane, contrary to the young pedestrians who considered both gaps in both lanes to decide whether or not to cross the two-way street. Old pedestrians tended to step into the street when only the near lane was safe: out of the 3024 decisions made by the 84 participants, 128 led to a collision, $65 \%$ of which were made by old participants in situations where the time gap was sufficient for them in the near lane $(3,4$, or $5 \mathrm{~s})$ but too short in the far lane (2 
s). Because old pedestrians mainly checked traffic approaching in the near lane before starting to cross, they could find out when reaching the middle that cars approaching from the opposite direction were too close. Even if they became aware of this, these non-optimal choices could not be compensated for by walking faster due to the declines in physical abilities (see e.g., Salzman, 2010). When required to change from walking at preferred speed to walking quickly, old people have been shown to fail to achieve the same increases in speed and stride length relative to the increases achieved by young adults (Shkuratova, Morris, \& Huxham, 2004). These motor difficulties could have led in the present experiment to collisions on the far side of the street for old pedestrians in particular.

It can be assumed that the observed visual exploration strategies and the ensuing crossing behaviors reflect diminished functional abilities. Because of perceptual and cognitive declines (see e.g., Ball, Owsley, Sloane, Roenker, \& Bruni, 1993; Poulter \& Wann, 2013; Salthouse, 1996, Salthouse et al., 2003), old pedestrians may not be able to process all information in the visual scene and so may consider only the closer scene when making their decision to cross a two-way street. Given their fear of falling (e.g., Scheffer, Schuurmans, Van Dijk, Van der hooft, \& De Rooij, 2008) and their need to keep their balance during walking (Woollacott, \& Tang, 1997), they also seem to allocate more attention to watching their steps as they cross, causing them to at least partly disregard the approaching traffic (Avineri, Shinar, \& Susilo, 2012). At signal-controlled intersections, old pedestrians have even been shown not to look at the traffic at all (Job, Haynes, Prabhakar, Lee \& Quach, 1998). Such an inadequate visual exploration strategy was also partly observed here in the non-signal-controlled crossings of the present experiment. There is evidence that old pedestrians often expect drivers to adapt to them (Dunbar et al., 2004).

Some difficulty handling the far lane were also observed in the young pedestrians, although not as numerous or serious as in the old participants because young people can 
compensate for some rare non-optimal choices by speeding up. Although lane differences were not observed in terms of collisions for young participants, they exhibited safer behaviors in the near lane and difficulty on the far lane in terms of hasty crossings and small safety margins.

The far-lane difficulties of older adults found in the present experiment are inconsistent with Dunbar's $(2005,2012)$ epidemiological analyses. This discrepancy can be explained by important age differences in the pedestrian samples studied, insofar as Dunbar found a high risk of near-side accidents in very old pedestrians over 85 years of age. In line with the idea that cognitive declines increase with age, the decision-making of very old pedestrians (over 85) can no longer be accurate and lead to collisions right from the near side of the street for the oldest pedestrians (Dunbar, 2005, 2012) or among people with Alzheimer's disease (Gorrie, Brown, \& Waite, 2008). In contrast, the results of the present study suggest that decision-making is only slightly affected in younger-old pedestrians under age 85 , with biased decisions favoring the near-side lane and thus collisions and behavioral difficulties mostly in the far lane. The question of near- versus far-side collisions among young and old pedestrians deserves further study in experiments involving a group of pedestrians over 85 years of age.

The old participants in the present experiment were also found to have difficulty safely handling situations where vehicles were approaching at a high speed. As a whole, they made a greater number of decisions that led to collisions when cars were approaching at $60 \mathrm{~km} / \mathrm{h}$ than at $40 \mathrm{~km} / \mathrm{h}$. Risky crossing decisions at the high approach speed were particularly observed in the near lane, most likely because the far lane was not taken into account by old participants. This effect of vehicle speed has been systematically observed in earlier studies using one-way traffic (Lobjois \& Cavallo, 2007; Oxley et al., 2005) and interpreted as the use of simplified heuristics based on vehicle distance and a neglect of speed information. 


\section{Conclusions}

The results of the present study brought out a greater risk of being involved in a collision for old pedestrians than for younger adults when crossing a two-way street. The most notable finding concerned to the high number of non-optimal decisions by old pedestrians with respect to the far lane. The most risky situation was when the near lane provided a safe gap for crossing but the far lane did not, because old pedestrians mainly checked for vehicles approaching in the near lane before crossing and could sometimes reach the middle of the street without looking at the far-side traffic at all.

Together with the use of simplifying speed-neglecting heuristics often reported in the literature (Lobjois \& Cavallo, 2007, 2009; Oxley et al., 2005) and also observed in the present experiment, the inadequate visual exploration strategies of older adults point to a substantial cognitive overload in the demanding situation of two-way street crossing. According to previous studies, this overload may be mainly related to attention deficits and reduced processing speed, both shown to predict unsafe crossing decisions by old pedestrians in oneway or in two-way situations (Dommes \& Cavallo, 2011; Dommes et al., 2013). Because sensorimotor performance becomes cognitively more demanding with advancing age (Lindenberger, Marsiske, \& Baltes, 2000; Woollacott, \& Shumway-Cook, 2002), the control of posture and gait while walking could also contribute to the too high attentional requirements of the two-way street-crossing task for old pedestrians, who suffer from limited attentional resources.

One of the most interesting results of the present experiment is that old people appear to be unable to compensate for these non-optimal and dangerous choices by speeding up. The higher crash risk of old pedestrians could actually be the result of two parallel difficulties (i) biased decisions (toward the near lane and the distance of approaching cars) and (ii) little possibility of compensation by walking faster. Beyond the well-known motor decrements 
with aging (see e.g., Shkuratova et al., 2004), the absence of compensation of decision making difficulties by walking quickly could also be linked to the need of old people to visually control their gait and balance, impeding them therefore to observe the approaching traffic while walking. Several papers clearly show that old people need to watch their steps to avoid a fall while walking (see e.g., Avineri et al., 2012) and this sensorimotor performance prioritization could be even at the cost of any other performance (see e.g., Shumway-Cook, Woollacott, Kerns, \& Baldwin, 1997).

The present findings could contribute to defining specific road-safety measures that could be implemented to counteract the difficulties of old pedestrians. One measure would be to increase the number of marked and/or signaled crossings (e.g., zebra, pelican and puffin crossings) and to make longer crossing-time allowances. Car-free islands in the middle of two-way streets could also considerably help old pedestrians cross the street. Islands lower their exposure to potential collisions by decreasing the time spent in the street, while also lightening the cognitive load of the street-crossing task by splitting it into two stages. Such islands mostly provide a safe place to pause in the middle of the street and allow pedestrians to visually explore the far side of the two-way street. Moreover, car-speed reduction measures are clearly important for pedestrian safety and are also recommended. Measures such as lowering speed limits in areas of high pedestrian activity should be considered.

The present findings also raise the question whether training programs are a route worth exploring as a supplement to the above safety regulations and pedestrian-friendly infrastructure measures. A possible effective approach could be to offer mixed behavioral and educational training, as already demonstrated for improving the safety of older adults in oneway street-crossing situations (Dommes \& Cavallo, 2012; Dommes, Cavallo, Vienne, \& Aillerie, 2012). 


\section{Acknowledgments}

This research was supported by grants from the French Road Safety Foundation (SEPIA Project). The authors are grateful to the young and old participants for their participation, interest, and cooperation. We would also like to thank Sabine Langevin for her help in running the experiment, and Isabelle Aillerie and Jacky Robouant for their help in setting up the simulator scenarios and visual scenes. The authors are grateful to Vivian Waltz for her English editing. 


\section{References}

Avineri, E, Shinar, D., \& Susilo, Y. (2012). Pedestrians' behaviour in cross walks: The effects of fear of falling and age. Accident Analysis and Prevention, 44(1), 30-34.

Ball, K, Owsley, C, Sloane, ME, Roenker, DL, \& Bruni, JR. (1993). Visual Attention

Problems as a Predictor of Vehicle Crashes among Older Drivers. Investigative Ophthalmology \& Visual Science, 34, 3110-3123.

Dommes, A., \& Cavallo, V. (2011). The role of perceptual, cognitive, and motor abilities in street-crossing decisions of young and older pedestrians. Ophthalmic and Physiological Optics, 31, 292-301.

Dommes, A., \& Cavallo, V. (2012). Can simulator-based training improve street-crossing safety for older pedestrians? Transportation Research Part F: Traffic Psychology and Behaviour, 15, 206-218.

Dommes, A., Cavallo, V., \& Oxley, J.A. (2013). Functional declines as predictors of risky street-crossing decisions in older pedestrians. Accident Analysis and Prevention, 59, 135-143.

Dommes, A., Cavallo, V., Vienne, F., \& Aillerie, I. (2012). Age-related differences in streetcrossing safety before and after training of older pedestrians. Accident Analysis and Prevention, 44, 42-47.

Dunbar, G. (2005). Using epidemiological data to address psychological questions about pedestrian behaviour. In: Underwood, G. (Ed.), Traffic and Transport Psychology: Theory and Application. Elsevier, Oxford, pp. 19²5.

Dunbar, G. (2012). The relative risk of nearside accidents is high for the youngest and oldest pedestrians. Accident Analysis and Prevention, 45, 517-521.

Dunbar, G., Holland, C.A., Maylor, E.A. (2004). Older Pedestrians: A Review. Department for Transport, London. 
Folstein, M.F., Folstein, S.E., \& McHugh, P.R. (1975). Mini-mental state: A practical method for grading the cognitive state of patients for the clinician. Journal of Psychiatric Research, 12 (3), 189`98.

Fontaine, H., \& Gourlet, Y. (1997). Fatal pedestrian accident in France: a typological analysis. Accident Analysis and Prevention, 29, 303-312.

Gorrie, C.A., Brown, J., \& Waite, P.M.E. (2008). Crash characteristics of older pedestrian fatalities: Dementia pathology may be related to 'at risk' traffic situations. Accident Analysis and Prevention, 40(3), 912-919.

Holland, C., \& Hill, R. (2010). Gender differences in factors predicting unsafe crossing decisions in adult pedestrians across the lifespan: a simulation study. Accident Analysis \& Prevention, 42, 1097-1106.

Job, R. F. S., Haynes, J., Prabhakar, T., Lee, S. H. V., \& Quach, J. (1998). Pedestrians at traffic light controlled intersections: Crossing behaviour in the elderly and nonelderly. In K. Smith \& B. G. Aitken \& R. H. Grzebieta (Eds.), Proceedings of the Conference on Pedestrian Safety (pp. 3-11). Canberra: Australian College of Road Safety and Federal Office of Road Safety.

Knoblauch, R.L., Pietrucha, M.T., \& Nitzburg, M. (1996). Field Studies of Pedestrian Walking Speed and Start-up Time, Transportation Research Record, 1538, 27-38.

Lindenberger, U., Marsiske, M., \& Baltes, P.B. (2000). Memorizing while walking: Increase in dual-task costs from young adulthood to old age. Psychology and Aging, 15, 417-436.

Lobjois, R., \& Cavallo, V. (2007). Age-related differences in street-crossing decisions: The effects of vehicle speed and time constraints on gap selection in an estimation task. Accident Analysis \& Prevention, 39, 934-943.

Lobjois, R., \& Cavallo, V. (2009). The effects of aging on street-crossing behavior: from estimation to actual crossing. Accident Analysis \& Prevention, 41, 259-267. 
Lobjois, R., Benguigui, N., \& Cavallo, V. (2013). The effects of age and traffic density on street-crossing behavior. Accident Analysis \& Prevention, 53, 166-175.

Observatoire National Interministériel de Sécurité Routiere (ONISR), 2011. La sécurité routière en France. Bilan de l’année 2011. La documentation Française, Paris.

Oxley, J.A., Fildes, B.N., Ihsen, E., Charlton, J.L., \& Day, R.H. (1997). Differences in traffic judgements between young and old adult pedestrians. Accident Analysis \& Prevention, $29,839-847$.

Oxley, J.A., Ihsen, E., Fildes, B.N., Charlton, J.L., \& Day, R.H. (2005). Crossing roads safely: An experimental study of age differences in gap selection by pedestrians. Accident Analysis \& Prevention, 37, 962-971.

Poulter, D.R., \& Wann, J.P. (2013). Errors in motion processing amongst older drivers may increase accident risk. Accident Analysis \& Prevention, 57, 150-156.

Salzman, B. (2010). Gait and balance disorders in older adults. American Family Physician, $82,61-68$.

Salthouse, T.A., (1996). The processing-speed theory of adult age differences in cognition. Psychology and Aging, 103, 403-428.

Salthouse, T.A., Atkinson, T.M., \& Berish, D.E. (2003). Executive functioning as a potential mediator of age-related cognitive decline in normal adults. Journal of Experimental Psychology: General, 132, 566-594.

Scheffer, A.C., Schuurmans, M.J., Van Dijk, N., Van der hooft, T., de Rooij, S.E. (2008). Fear of falling: measurement strategy, prevalence, risk factors and consequences among older persons. Age and Ageing, 37, 19²4.

Shkuratova, N., Morris, M.E., \& Huxham, F. (2004). Effects of age on balance control during walking. Archives of Physical Medicine and Rehabilitation, 85, 582-8. 
Shumway-Cook, A., Woollacott, M., Kerns, K. A., \& Baldwin, M. (1997). The effects of two types of cognitive tasks on postural stability in older adults with and without a history of falls. Journal of Gerontology: Medical Sciences, 52A, M232 - M240.

Snowden, R.J., \& Kavanagh, E. (2006). Motion perception in the aging visual system: minimum motion, motion coherence, and speed discrimination thresholds. Perception, $35,9-24$.

Tabachnick, B. G., \& Fidell, L. S. (1989). Using multivariate statistics (2 ${ }^{\text {nd }}$ ed.). New York: Harper Collins.

Woollacott, M. H., \& Tang, P. F. (1997). Balance control during walking in the older adult: Research and its implications. Physical Therapy, 6, 646-660.

Woollacott, M. H., \& Shumway-Cook, A. (2002). Attention and the control of posture and gait: a review of an emerging area of research. Gait and Posture, 16, 1-14.

Zhuang, X., \& Wu, C. (2011). Pedestrians' crossing behaviors and safety at unmarked roadway in China. Accident Analysis \& Prevention, 43, 1927-1936.

Zhuang, X., \& Wu, C. (2012). The safety margin and perceived safety of pedestrians at unmarked roadway. Transportation Research Part F: Traffic Psychology and Behaviour, 15, 119-131. 


\section{Figure captions}

Figure 1. Schematic view of the street-crossing simulator and the trials proposed to participants.

Figure 2. Percentage of accepted crossings for each age group as a function of the time gap available in each lane.

Figure 3. Mean number of looks and mean looking time (in seconds) before crossing as a function of age group and lane where vehicles approached. Vertical bars represent standard deviations. 
Table1. Time gaps simultaneously available between two target cars in the traffic flow (in s.).

\begin{tabular}{|l|l|l|llll|llll|llll|llll|}
\hline Near lane (gap in s) & 1 & \multicolumn{4}{|c|}{2} & \multicolumn{4}{|c|}{3} & \multicolumn{4}{|c|}{4} & \multicolumn{3}{|c|}{5} \\
\hline Far lane (gap in s) & 1 & 2 & 3 & 4 & 5 & 2 & 3 & 4 & 5 & 2 & 3 & 4 & 5 & 2 & 3 & 4 & 5 \\
\hline
\end{tabular}

[Note: Gaps in the far lane were updated according to the participant's walking speed (as measured previously across multiple trials) so that gaps from $1 \mathrm{~s}$ to $5 \mathrm{~s}$ were available in the far lane at the moment when the participant would have been in the middle of the street.] 
Table 2. Mean percentage of collisions. Standard deviations are shown in parentheses.

\begin{tabular}{|c|c|c|c|c|}
\hline & Young & Younger-old & Older-old & \\
\hline \multirow[t]{2}{*}{ Near lane $-40 \mathrm{~km} / \mathrm{h}$} & 0 & 1.16 & 1.75 & \\
\hline & $(0)$ & $(3.53)$ & $(4.27)$ & \\
\hline \multirow[t]{2}{*}{ Near lane $-60 \mathrm{~km} / \mathrm{h}$} & 0 & 0.55 & 2.74 & \\
\hline & $(0)$ & $(2.91)$ & $(5.26)$ & \\
\hline \multirow[t]{2}{*}{ Far lane $-40 \mathrm{~km} / \mathrm{h}$} & 0.69 & 4.03 & 5.49 & \\
\hline & $(2.95)$ & $(7.84)$ & $(9.56)$ & \\
\hline \multirow[t]{2}{*}{ Far lane $-60 \mathrm{~km} / \mathrm{h}$} & 2.43 & 6 & 12.14 & \\
\hline & $(4.15)$ & $(7.51)$ & $(10.13)$ & \\
\hline \multirow[t]{2}{*}{ Age-group comparison } & 0.78 & 2.93 & 5.53 & \\
\hline & $(1.78)$ & $(5.45)$ & $(7.31)$ & \\
\hline \multicolumn{4}{|l|}{ Lane comparisons by group } & Mean \\
\hline \multirow[t]{2}{*}{ Near } & 0 & 0.86 & 2.24 & 1.03 \\
\hline & $(0)$ & $(3.22)$ & $(4.77)$ & $(2.66)$ \\
\hline \multirow[t]{2}{*}{ Far } & 1.56 & 5.01 & 8.82 & 5.13 \\
\hline & $(3.55)$ & $(7.67)$ & $(9.84)$ & $(7.02)$ \\
\hline \multicolumn{5}{|l|}{ Speed comparisons by group } \\
\hline \multirow[t]{2}{*}{$40 \mathrm{~km} / \mathrm{h}$} & 0.35 & 2.60 & 3.62 & 2.19 \\
\hline & $(1.47)$ & $(5.68)$ & (6.92) & $(4.69)$ \\
\hline \multirow[t]{2}{*}{$60 \mathrm{~km} / \mathrm{h}$} & 1.22 & 3.27 & 7.44 & 3.98 \\
\hline & $(2.08)$ & $(5.21)$ & (7.7) & (4.99) \\
\hline
\end{tabular}


Table 3. Mean crossing time (in seconds). Standard deviations are shown in parentheses.

\begin{tabular}{|c|c|c|c|c|}
\hline & Young & Younger-old & Older-old & \\
\hline \multirow[t]{2}{*}{ Near lane $-40 \mathrm{~km} / \mathrm{h}$} & 2.26 & 2.25 & 2.32 & \\
\hline & $(0.36)$ & $(0.26)$ & $(0.26)$ & \\
\hline \multirow[t]{2}{*}{ Near lane $-60 \mathrm{~km} / \mathrm{h}$} & 2.18 & 2.26 & 2.37 & \\
\hline & $(0.24)$ & $(0.22)$ & $(0.31)$ & \\
\hline \multirow[t]{2}{*}{ Far lane $-40 \mathrm{~km} / \mathrm{h}$} & 1.63 & 1.90 & 1.94 & \\
\hline & $(0.11)$ & $(0.15)$ & $(0.22)$ & \\
\hline \multirow[t]{2}{*}{ Far lane $-60 \mathrm{~km} / \mathrm{h}$} & 1.64 & 1.95 & 2.02 & \\
\hline & $(0.12)$ & $(0.18)$ & $(0.25)$ & \\
\hline \multirow[t]{2}{*}{ Age-group comparison } & 1.93 & 2.09 & 2.16 & \\
\hline & $(0.21)$ & $(0.20)$ & $(0.26)$ & \\
\hline \multicolumn{4}{|l|}{ Lane comparisons by group } & Mean \\
\hline \multirow[t]{2}{*}{ Near } & 2.22 & 2.25 & 2.35 & 2.27 \\
\hline & $(0.30)$ & $(0.24)$ & $(0.29)$ & $(0.27)$ \\
\hline \multirow[t]{2}{*}{ Far } & 1.64 & 1.93 & 1.98 & 1.85 \\
\hline & $(0.12)$ & $(0.16)$ & $(0.23)$ & $(0.17)$ \\
\hline \multicolumn{5}{|l|}{ Speed comparisons by group } \\
\hline \multirow{2}{*}{$40 \mathrm{~km} / \mathrm{h}$} & 1.95 & 2.07 & 2.13 & 2.05 \\
\hline & $(0.24)$ & $(0.20)$ & $(0.24)$ & $(0.23)$ \\
\hline \multirow[t]{2}{*}{$60 \mathrm{~km} / \mathrm{h}$} & 1.91 & 2.11 & 2.20 & 2.07 \\
\hline & $(0.18)$ & $(0.20)$ & $(0.28)$ & $(0.22)$ \\
\hline
\end{tabular}


Table 4. Mean safety margin (in seconds). Standard deviations are shown in parentheses.

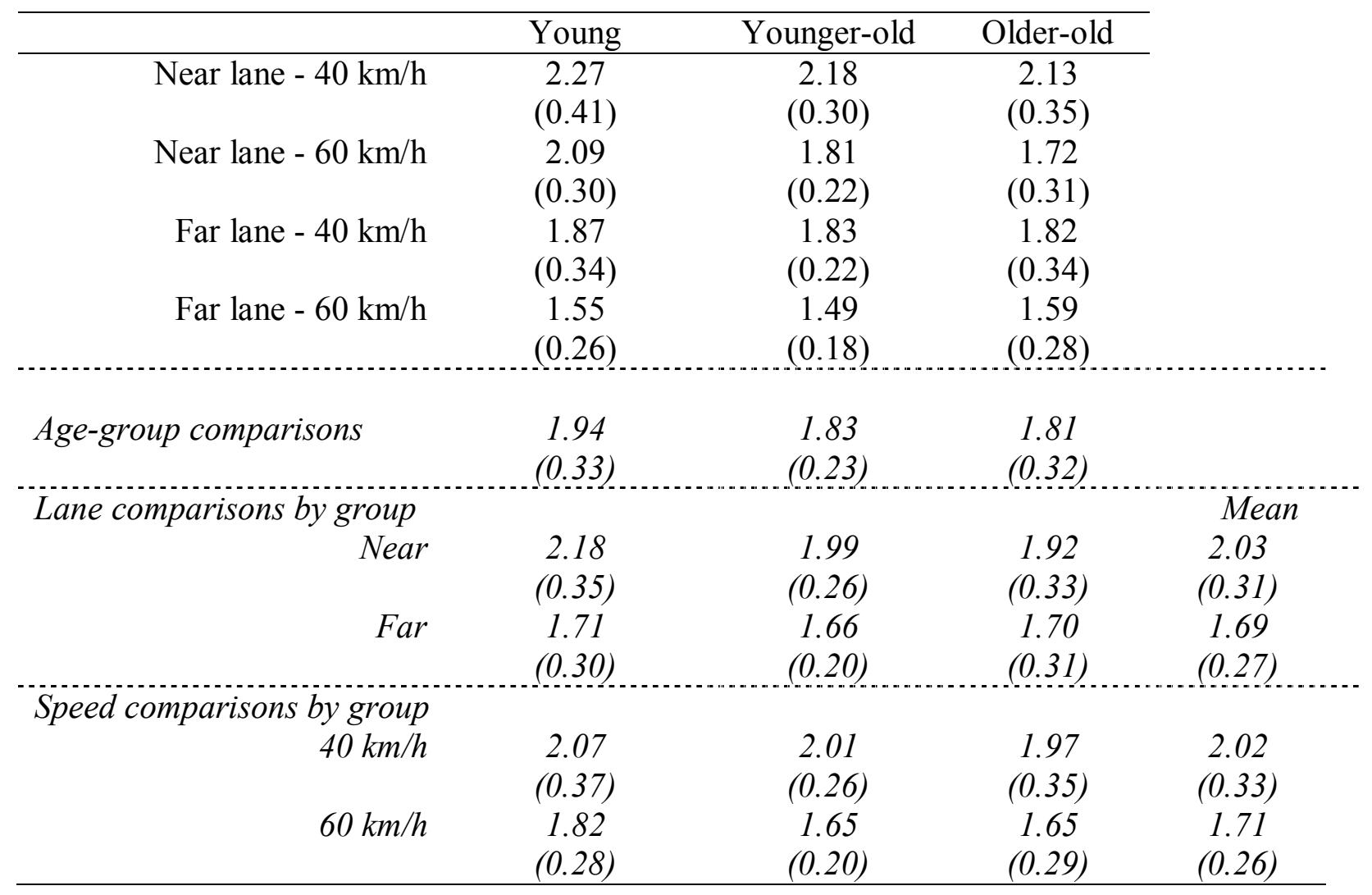

